\title{
Complement 4 levels of a 4-year-old girl with angioedema
}

A 4-year-old girl was admitted due to erythema marginatum like pruritic rash over the entire body surface. She had a history of recurrent both arms swelling for 1 year prior to admission. However, she denied any history of allergic disease or family medical history. On the second day of admission, she developed a fever $\left(38.5^{\circ} \mathrm{C}\right)$ and severe generalized abdominal pain, which improved on the next day. Subsequently, her hands and feet began to swell, suggesting angioedema (AE) (Table 1).

This study was approved by the Institutional Review Board (IRB) of the Catholic University of Korea, Daejeon St Mary's Hospital (IRB No. DC18ZESI0030).

What is the best screening test to exclude hereditary angioedema (HAE) on the 4-year-old gilr with recurrent anigoedema?
(1) $\mathrm{C} 4$
(2) C1-esterase inhibitor (C1-INH) activity
(3) C1-INH level
(4) Total IgE and specific IgE test

\section{Test characteristics of the patient}

The patient underwent testing for complement 4 (C4) levels because she had $\mathrm{AE}$ with a history of suspected recurrent $\mathrm{AE}$

Table 1. Patient's laboratory values and reference ranges

\begin{tabular}{lccc}
\hline Variable & $\begin{array}{c}\text { Admission } \\
\text { 1st day }\end{array}$ & $\begin{array}{c}\text { Admission } \\
\text { 3rd day }\end{array}$ & $\begin{array}{c}\text { Reference } \\
\text { range }\end{array}$ \\
\hline Hemoglobin $(\mathrm{g} / \mathrm{dL})$ & 13.2 & - & $11.5-13.5$ \\
White blood cell count $(/ \mu \mathrm{L})$ & 13,700 & - & $5,000-14,500$ \\
Segmental neutrophil $(\%)$ & 67.5 & - & $35-74$ \\
Lymphocyte & 22.9 & - & $20-51$ \\
Eosinophil & 0.3 & - & $0-5$ \\
Total protein & 6.0 & 4.5 & $6.7-8.0$ \\
Albumin & 4.0 & 3.1 & $4.0-5.0$ \\
AST $(\mathrm{U} / \mathrm{L})$ & 38 & 23 & $0-31$ \\
ALT $(\mathrm{U} / \mathrm{L})$ & 15 & 20 & $0-31$ \\
CRP & 1.64 & 8.7 & $0-0.5$ \\
C3 $(\mathrm{mg} / \mathrm{dL})$ & - & 93 & $86-160$ \\
C4 (mg/dL) & - & 6.2 & $17-45$ \\
CH50 $(\mathrm{U} / \mathrm{mL})$ & - & 3.5 & $23-46$
\end{tabular}

AST, aspartate aminotransferase; ALT, alanine aminotransferase; CRP, C-reactive protein; $\mathrm{C} 3$, complement 3; C4, complement 4; $\mathrm{CH} 50,50 \%$ hemolytic complement. events. C4 level is an important screening test for diagnosing $\mathrm{AE}$ associated with C1-INH. ${ }^{1)}$ In this case, because $\mathrm{C} 3$ is normal and $\mathrm{C} 4$ is decreased, C1-INH activity and level test were performed. C1-INH activity was reduced under $50 \%$ of the normal range and the C1-INH level was decreased (Table 2). Hereditary angioedema has been associated with decreased C1-INH function in patients with recurrent edema involving the skin, intestine, and airway. HAE is an autosomal dominant disease caused by a mutation in the SERPING 1 gene on chromosome 11 (11q12q13.1), leading to a deficiency or functional inactivation of C1$\mathrm{INH}^{2,3)}$ Although type $3 \mathrm{HAE}$ with normal C1-INH function is rarely reported, a majority of patients with HAE have decreased C1-INH function. Therefore C1-INH activity and level test are essential to confirm HAE. HAE is mainly classified as type $1(80 \%-85 \%)$ and type $2(15 \%-20 \%)$. ${ }^{4,5)}$ Type $1 \mathrm{HAE}$ has low C1-INH level and activity, but type 2 HAE has normal or high C1-INH level and decreased activity. ${ }^{6} \mathrm{C} 4$ is always low in majority of patients. Algorithm for diagnosis recommends screening with C4 initially, followed by C1-INH activity and then level if required. ${ }^{7,8)}$ This patient could be diagnosed early with HAE by examination of $\mathrm{C} 4$ and $\mathrm{C} 1-\mathrm{INH}$ with recurrent $\mathrm{AE}$. It is noteworthy that symptoms of HAE can also be expressed in young children, as in this patient. Furthermore, her symptoms such as arm swelling had started since the age of 3 . Therefore, medical staff should actively suspect HAE and make efforts for early diagnosis by conducting $\mathrm{C} 4$ and $\mathrm{C} 1-\mathrm{INH}$ testing on even very young children.

\section{Usefulness of genetic testing}

HAE is an autosomal dominant disease with $25 \%$ de novo mutation. ${ }^{9)}$ Genetic testing is not essential for the diagnosis of

Table 2. Complement and C1 esterase inhibitor (C1-INH) levels of the patient and her mother

\begin{tabular}{lcc}
\hline Variable & $\begin{array}{c}\text { Patient } \\
\text { (reference range) }\end{array}$ & $\begin{array}{c}\text { Patient's mother } \\
\text { (reference range) }\end{array}$ \\
\hline C1-INH (mg/dL) & $10(21-39)$ & $<2.9(21-39)$ \\
C1-INH activity $\%)$ & $<25(70-130)$ & $<25(70-130)$ \\
C3 $(\mathrm{mg} / \mathrm{dL})$ & $93(86-160)$ & $106.7(90-180)$ \\
$\mathrm{C} 4(\mathrm{mg} / \mathrm{dL})$ & $6.2(17-45)$ & $2.2(10-40)$ \\
$\mathrm{CH} 50(\mathrm{U} / \mathrm{mL})$ & $3.5(23-46)$ & $<10(32-58)$ \\
\hline
\end{tabular}

C3, complement 3; C4, complement 4; CH50, 50\% hemolytic complement. 
HAE, but is helpful in a confirming HAE from AAE. ${ }^{10)}$ It is also useful in diagnosing asymptomatic family members and in predicting the likelihood of disease development in offspring and in coping with future emergent situations.

\section{Application of test results to this patient}

Our patient and her mother showed reduced C4, C1-INH activity and level (Table 2). Therefore, they were diagnosed as type 1 HAE according to the diagnostic criteria. ${ }^{2)}$ They underwent genetic testing (Sanger sequencing), which revealed a missense mutation (c.1427C > T) of the SERPING 1 gene.

\section{Treatment and clinical course in the patient and her family}

On-demand therapeutic agents consist of plasma-derived C1INH (PdC1-INH, Berinert or Cinryze), recombinant human C1-INH (rhC-INH, Ruconest), Kallikrein-inhibitor (Ecallantide) and bradykinin-receptor antagonist (icatibant). Among them, PdC1-INH and icatibant is the approved drug for on-demand treatment in children. However, only icatibant is currently available in Korea, otherwise solvent detergent treated plasma or fresh frozen plasma can be used as second-line treatment. PdC1-INH is also preferred for long-term prophylaxis. When it is unavailable, antifibrinolytics (i.e., tranexamic acid) are preferred above androgens in children. Our patient did not present with AE after the initial diagnosis at 4 years old. However, colicky abdominal pain recurred every once or twice a month. The frequency of abdominal pain decreased sharply after 6 years old. She did not use any prophylaxis medication or on-demand medication. When the patient was 9 years old, the patient's mother was diagnosed with breast cancer and was given tamoxifen as part of her treatment regimen. Soon after medication, the patient's mother developed severe abdominal pain with hand swelling that lasted 24 hours, which recurred once a month. However, there was no urticaria and pruritus. Laboratory studies were performed and she was diagnosed with HAE, too (Table 2). Her mother started long-term prophylaxis with tranexamic acid and has terminated her prophylaxis after discontinuing tamoxifen because the incidence of abdominal pain was reduced.

If our patient was not diagnosed at an early age of 4 years old, the diagnosis of HAE might have been delayed because $\mathrm{AE}$ did not occur since then. In this respect, if HAE is suspected, an active diagnostic approach should be made.

Answer: (1) C4

See the Commentary "Hereditary angioedema in childhood" in Volume 63 on page 18.

\section{Conflicts of interest}

No potential conflict of interest relevant to this article was reported.

Soyoung Shin, $\mathrm{MD}, \mathrm{PhD}^{1}$, Yoon Tae Lee, $\mathrm{MD}^{2}$, Kyung Yil Lee, $\mathrm{MD}, \mathrm{PhD}^{2}$, Joonhong Park, $\mathrm{MD}, \mathrm{PhD}^{1}$, Jae Ho Lee, $\mathrm{MD}, \mathrm{PhD}^{3}$, Eun Ae Yang, $\mathrm{MD}, \mathrm{PhD}^{2}$

${ }^{1}$ Department of Laboratory Medicine, Daejeon St. Mary's Hospital, College of Medicine, The Catholic University of Korea, Daejeon; ${ }^{2}$ Department of Pediatrics, Daejeon St. Mary's Hospital, College of Medicine, The Catholic University of Korea, Daejeon; ${ }^{3}$ Department of Pediatrics, Joey Hospital, Daejeon, Korea

Corresponding author: Eun Ae Yang, MD. Department of Pediatrics, Daejeon St. Mary's Hospital, College of Medicine, The Catholic University of Korea, 64 Daeheung-ro, Jung-gu, Daejeon 34943, Korea

凶 E-mail: anni79@catholic.ac.kr, https://orcid.org/0000-00034787-5763

\section{References}

1. Shin M, Ahn K. A case of hereditary angioedema in a 7-year-old Korean girl. Allergy Asthma Immunol Res 2013;5:59-61.

2. Agostoni A, Aygören-Pürsün E, Binkley KE, Blanch A, Bork K, Bouillet L, et al. Hereditary and acquired angioedema: problems and progress: proceedings of the third $\mathrm{C} 1$ esterase inhibitor deficiency workshop and beyond. J Allergy Clin Immunol 2004;114(3 Suppl):S51-131.

3. Sim DW, Park KH, Lee JH, Park JW. A case of type 2 hereditary angioedema with SERPING1 mutation. Allergy Asthma Immunol Res 2017;9: 96-8.

4. Sabharwal G, Craig T. Pediatric hereditary angioedema: an update. F1000Res 2017;6. pii: F1000 Faculty Rev-1205. https://doi.org/10.12688 /f1000research.11320.1.

5. Jung JW, Suh DI, Park HJ, Kim S, Kwon HS, Yang MS, et al. Clinical features of hereditary angioedema in Korean patients: a nationwide multicenter study. Int Arch Allergy Immunol 2018;176:272-9.

6. Zuraw BL. Current and future therapy for hereditary angioedema. Clin Immunol 2005;114:10-6.

7. Bowen T, Cicardi M, Farkas H, Bork K, Longhurst HJ, Zuraw B, et al. 2010 International consensus algorithm for the diagnosis, therapy and management of hereditary angioedema. Allergy Asthma Clin Immunol 2010;6:24.

8. Bork K. Diagnosis and treatment of hereditary angioedema with normal C1 inhibitor. Allergy Asthma Clin Immunol 2010;6:15.

9. Bowen T, Cicardi M, Bork K, Zuraw B, Frank M, Ritchie B, et al. Hereditary angiodema: a current state-of-the-art review, VII: Canadian Hungarian 2007 International Consensus Algorithm for the Diagnosis, Therapy, and Management of Hereditary Angioedema. Ann Allergy Asthma Immunol 2008;100(1 Suppl 2):S30-40.

10. Weiler CR, van Dellen RG. Genetic test indications and interpretations in patients with hereditary angioedema. Mayo Clin Proc 2006;81:958-72. 